Article

\title{
The Effect of Geographical Environment Factors on the Right Ventricular Diameter Reference Value Based on the Factor Analysis
}

\author{
Yan Liu ${ }^{1, *}$ and Miao Ge ${ }^{2}$ \\ 1 Rural planning and Architectural Engineering, Shangluo University, 10 east beixin street, \\ 726000 Shangluo, China \\ 2 Institute of Healthy Geography, College of Tourism and Environment, \\ ShaanXi Normal University, 199 South Chang'an Road, 710062 Xi'an, China; \\ gemiao@snnu.edu.cn \\ * Correspondence: liuyan_ly2004@126.com
}

\begin{abstract}
Aim: To analysis the relationship between healthy adults right ventricular diameter (RVD) and geographical factors. Location: China's 22 provinces, municipalities and autonomous regions. Methods: Using correlation analysis the relationship between RVD and nine geographic factors, build predictive models by factor analysis. Results: There is significant correlation between RVD and geographical factors, and the annual average temperature is most relevant geographical factors, a predictive model was built by factor analysis: $\hat{Y}=19.46+$ $0.0007072 \mathrm{X} 1+0.001034 \mathrm{X} 2-0.05412 \mathrm{X} 3-0.001405 \mathrm{X} 4-0.0006351 \mathrm{X} 5+0.02903 \mathrm{X} 6+$ $0.01243 \times 7-0.01033 \times 8+0.03816 \times 9 \pm 0.63$. Then using Kriging interpolation interpolate the geographical distribution of Chinese healthy adult right ventricular diameter reference value in ArcGIS software. Main Conclusion: If geographic factors can be derived in anywhere of China, RVD can be calculated by the model, you can also get RVD from geographical distribution.
\end{abstract}

Keywords: factor analysis; geographical factors; right ventricular diameter

\section{Introduction:}

For a long time, the majority of people think ventriculus dexter is attacheded on Ventriculus sinister to function, and due to the right ventride anatomy is compicated anatomy, indiastolic fitting in blood flow affected by respiratory cycle, lead to its functional test is relatively difficult. So far still no any recognized quantitative evaluation method and index about ventriculus dexter, There has been insufficient research on cardiac surgery effect on right ventricular function. In recent years, the importance of the function of the right rentriclular in heart disease and cardiac surgery has gradually understood. More and more research has proved the right rentricular function directly affects the function of the entire circulatory system. Right 
rentriclular function is very important for the prognosis of various types of cardiac surgery.

Along with the advance of echocardiogram diagnostic techniques. the right rentriclular function and volume evaluation method of continuous improvement. The evaluation has been more and more attract people's attention..How can fast and accurate evaluation of the right rentriclular volume and functions have vital significance in clinical appitcation of genetic.

For lack of unified standard reference index of RVD at home and abroad (The right ventricle Diminished).in the practical application of the medical diagnosis, the right ventricle diminished reference value exist differences. Many people tested the reference value about right ventride diminished in the region, and many scholars also investigated and studied the change of RVD reference value of healthy people from the plains moved to plateau. But the RVD reference value's relationship with the environment research has not been reported.

In addition, geographical environment is a complicated synthesis. China is a vast country, has vagaries of climate, complicated topography. Considering the influence of environmental factors about the right ventricle diminished of the healthy adult objectivity is bigger, and maybe has different influence level ,this paper use factor analysis to studied the relationship about the RVD with geographical environment that the healthy adults in China, found some regularity and analysis in further.

\section{Materials and Methods}

\section{The RVD (The right Ventricle diminished reference value)}

Derive RVD by retriving literature databases, such as China National Knowledge Infrastructure, WAN FANG DATA, Super Star Digital Library. Finally 51 cities (county) of hospital and the relevant research organization in China has been collected. There are 3594 samples of healthy adults, age range from 17 to 84, these organizations altogether are 22 provinces, cities, municipalities distributed in China , and respecitively are

Beijing ,Liaoning,Tianjin,Hebei,Henan,Tibet,Sinkiang,Anhui,Shanxi,Jiangxi,Ningxia, Qinghai,Szechwan,Chongqing,Hunan,Shanghai,Fujian,Zhejiang,Jiangsu,Yunnan,Gua ngdong. The region distribution in the large part of China,the eastern plain areas of the data are more than the western plateau region ones, so can better to reflece the 
geographical distribution regularity of the normal RVD reference value.

RVD reference value all was determined by $2 \mathrm{D}$ echocardiography measurements . This article selected exclusion standard of healthy people: congenital heart disease ,clarity of rheumatic heart disease ,secondary hypertension ,patients with chronic lung disease,Heavier patients with peripheral vascular disease and symptons .High blood pressure and left heart systolic dysfunction and unstable condition. kidney failure(plasma creatinine $>2.5 \mathrm{~g} / \mathrm{I}$ ).For severe liver disease(Aspertate aminotransferase or Alt $>$ three times the normal) .stroke patients within 3 months . blood disease. diabetes mellitus ,Hyperthyroidism, tuberculosis and the cavity structure have an impact on disease patients.

\section{The selection of geographic factors}

Geographical factors data are derived from China meteorological science data sharing service (http://cdc.cma.gov.cn). All the geographical data of index are average of nearly 30 years. The paper selected 9 relative geographical indicators to closely connect with human body physiology. - Altitude (m), annual sunlight ratio(h)、 annual temperatures $\left({ }^{\circ} \mathrm{C}\right)$ 、 annual average relative humidity $(\%)$ 、 annual precipitation $(\mathrm{mm})$ 、 annual range of temperature $\left({ }^{\circ} \mathrm{C}\right)$ 、 annual average wind $\operatorname{speed}(\mathrm{m} / \mathrm{s})$, longitude $\left({ }^{\circ}\right)$ and latitude $\left(^{\circ}\right)$ are represented by $\mathrm{X}_{1}, \mathrm{X}_{2}, \mathrm{X}_{3}, \mathrm{X}_{4}, \mathrm{X}_{5}, \mathrm{X}_{6}, \mathrm{X}_{7}, \mathrm{X}_{8}, \mathrm{X}_{9}$.

\section{Result}

\section{1 correlation analysis}

Correlation analysis is to study whether there is some kind of dependence between phenomena, explored the related direction and the related degree through have dependencies on specific phenomenon, is the study of random variables of the relationship between a statistical method.

Use adults of right ventricle diminished reference value as the dependent variable, the geographical indicator on 9 charges as independent, use SPSS 18.0 statistical analysis software for correlation analysis, work out at adults right ventricle diminished reference value and single phase relationship with various geographical indicators $r$ and $\mathrm{p}$ values, from this we can judged the relationship about the healthy adult right ventricle diminished reference value with geographical factors of the results in table 1. 
$\mathrm{P} \leq 0.01$ shows very significant correlation; $0.01<\mathrm{P} \leq 0.05$ shows significantly related; $\mathrm{P}>0.05$ shows did not correlate significantly. The results can be seen, that significantly related between the annual average temperature $\left(\mathrm{X}_{3}\right)$, annual average relative humidity $\left(\mathrm{X}_{4}\right)$ and the RVD reference value, the correlation is significant that the altitude $\left(\mathrm{X}_{1}\right)$ 、 annual sunshine duration $\left(\mathrm{X}_{2}\right)$ 、 annual precipitation $\left(\mathrm{X}_{5}\right)$ with the healthy adults right ventricle diminished reference value. That shows did not correlate significantly between the RVD reference value and annual range of temperature $\left(\mathrm{X}_{6}\right)$ 、 annual average wind $\operatorname{speed}\left(\mathrm{X}_{7}\right)$ 、 longitude $\left(\mathrm{X}_{8}\right)$ 、 latitude $\left(\mathrm{X}_{9}\right)$.

The RVD reference value increased with the increase of altitude $\left(\mathrm{X}_{1}\right)$ and annual sunshine duration $\left(\mathrm{X}_{2}\right)$, were positive correlation. It is decreased with the decrease of annual average temperature $\left(\mathrm{X}_{3}\right)$ 、 annual average relative humidity $\left(\mathrm{X}_{4}\right)$ and annual precipitation( $\left.\mathrm{X}_{5}\right)$, were negative correlation. Thus we find that the geographical environment effects on the RVD is obvious, with the change of geographical elements, the RVD reference value of adults will also have certain changes in our country.

\section{Factor Analysis}

Factor Analysis was first put forward by a British psychologist C.E Spearman .It is a generalization of the principal component analysis, it comes from the matrix related to the study of the internal dependencies ,put some complicated relationship of variables comes a representative and hidden variable dimension reduction method of multivariate statistical analysis.

Geographical environment included climate、 land 、 rivers 、 lakes 、mountains 、 minerals , animals and plant resources, a natural complex that is constituted a variety of natural elements, interaction between each geographic elements, connect with each other, but the impact on some physiological indexes of hard to explain with a single statement. Factor analysis can be found in a group of data is relevant and hard to explain, find a few meaningful on concept, independent to each other, and can influence the raw data of common factors, can put the relation indexes by factors analysis divided into a class, correlation between the different classes are reduced.

Therefore, this article use factor analysis method to study the relationship about 9 geographical indicators with the healthy adults RVD reference value, use the ideas of 
dimension reduction, by the research within the original variable correlation matrix dependencies, put some complicated relation of the variables expressed as common factor and which only has acted to a variable of special factor linear combination.

\subsection{Judging the conditions of the variable factor analysis}

Premise condition is that correlations between variables about use the factor analysis, before that, judging whether factor analysis is appropriate, there are two main methods to judge the condition: (1) The relationship between independent variables of the computer, it has practical significance for the factor analysis if most of variables correlation coefficient absolute value is greater than 0.3.(2)experiment with the statistical magnitude of KMO and Bartlett's spherical inspection to decide that is generally. believed as the effect is better when $\mathrm{KMO}>0.9$, Effect can be more than when $\mathrm{KMO}>0.7$, and when $\mathrm{KMO} \leqslant 0.5$ then are not suitable for factor analysis.

The article selected 9 single - phase relationship between geographical indicators matrix and the appropriate measurements of $\mathrm{KMO}$ and Bartlett's spherical check value as follows, table 2 and table 3 .

By the above two tables can be seen that the vast majority of geographical indicators of the correlation coefficient between the absolute value is greater than 0.3; and the 9 charges of geographical environment indicators KMO moderate sampling measurements for $0.633>0.5$, Bartlett's spherical inspection for 0.000 . In conclusion, for this article selected factor analysis of 9 geographical indicators is feasible.

\section{2 factor extraction}

Select geographic environmental indicators $\mathrm{X}_{1}, \mathrm{X}_{2}, \mathrm{X}_{3}, \mathrm{X}_{4}, \mathrm{X}_{5}, \mathrm{X}_{6}, \mathrm{X}_{7}, \mathrm{X}_{8}, \mathrm{X}_{9}$, as

an original variables , using SPSS software extracted common factors, shown in (table 4 ,figure 1), This is the main composition analysis. That is statistical method through the dimension reduction process, make a certain correlation between the initial variables in to a set of uncorrelated indicators. With less index was used to instead and reacted more information, the processing method is mathematically linear transformation.

Statistical information table of main component including: characteristic value, the contribution rate of each principal component and accumulation contribution rate, from big to small order, and from table 4 shows that the eigenvalues of the first three factors respectively are $4.664,2.322,1.031$, the cumulative contribution rate reached $89.067 \%$, meet the cumulative variance contribution rate $>70 \%$ or principle of characteristic value $\geqslant 1$. 
See Fig 1 again, the scree plot is on the decline, the first 3 characteristic values change quickly. The 4,5,6,7,8,9 leveled off, combing with the characteristic root curve infection point and characteristic root value, thus to extract the first three principal components instead of the original variable principal component analysis.

To sum up, choose three common factors(expressed as F1,F2,F3) instead of nine geographical indicators to studies the relationship about right ventricular diameter reference value of adults and geographical environment.

After communality than refers to extract common factor, the proportion of the original variables are extracted respectively in the information, or variance of the original variables is determined by the common factor in proportion, its value greater(0-1), indicate that more the variable can be factor suggests .shown in the table 5 below, the nine original variable are the generality of the above 0.5 , and most of the more than 0.7 ,It's more about extraction of three common factor is able to reflect objectively the main information of original variables.

\subsection{3 factor score and regression equation}

The table 6 is component score coefficient matrix, use the regression method to calculate factor score coefficient, and can be obtained the expression about common factors F1,F2,F3 with the standardization of original variables values(std Xi, $\mathrm{i}=1,2, \cdots \cdots, 9)$

$$
\begin{aligned}
& >\mathrm{F}_{1}=-0.242 \mathrm{std} \mathrm{X}_{1}-0.229 \mathrm{std} \mathrm{X}_{2}+0.210 \mathrm{std} \mathrm{X}_{3}+0.207 \mathrm{std} \mathrm{X}_{4}+0.154 \mathrm{std} \\
& \mathrm{X}_{5}+0.051 \mathrm{std} \mathrm{X}_{6}-0.068 \mathrm{std} \mathrm{X}_{7}+0.158 \mathrm{std} \mathrm{X}_{8}-0.041 \mathrm{std} \mathrm{X}_{9} \\
& >\mathrm{F}_{2}=-0.308 \mathrm{std} \mathrm{X}_{1}-0.062 \mathrm{std} \mathrm{X}_{2}-0.011 \mathrm{std} \mathrm{X}_{3}+0.040 \mathrm{~d} \mathrm{X}_{4}-0.164 d \mathrm{X}_{5}+ \\
& 0.465 \mathrm{~d} \mathrm{X}_{6}-0.145 \mathrm{~d} \mathrm{X}_{7}+0.139 \mathrm{std} \mathrm{X}_{8}+0.376 \mathrm{std} \mathrm{X}_{9} \\
& >\mathrm{F}_{3}=0.027 \mathrm{std} \mathrm{X}_{1}+0.363 \mathrm{std} \mathrm{X}_{2}-0.018 \mathrm{std} \mathrm{X}_{3}-0.109 \mathrm{std} \mathrm{X}_{4}+0.134 \mathrm{std} \mathrm{X}_{5}- \\
& 0.114 \mathrm{std} \mathrm{X}_{6}+0.762 \mathrm{std} \mathrm{X}_{7}+0.271 \mathrm{std} \mathrm{X}_{8}-0.071 \mathrm{std} \mathrm{X}_{9}
\end{aligned}
$$

The standard variable formula is $\operatorname{stdXi}=(\mathrm{Xi}-\partial i) / \delta i, \partial i$ is the average of the $\mathrm{Xi}$, $\delta i$ is the standard deviation of the Xi. Therefore, according to the description of the original variables statistics, can get the original variable standard index variable is:

$$
\begin{aligned}
& \operatorname{std} X_{1}=\left(X_{1}-1006.178\right) / 1215.0522 \\
& \operatorname{std} X_{2}=\left(X_{2}-2365.854\right) / 584.5339 \\
& \operatorname{std} X_{3}=\left(X_{3}-12.358\right) / 4.8139 \\
& \operatorname{std}_{4}=\left(X_{4}-62.80\right) / 15.308
\end{aligned}
$$




$$
\begin{aligned}
& \operatorname{std}_{5}=\left(X_{5}-737.92\right) / 476.596 \\
& \operatorname{std}_{6}=\left(X_{6}-24.61\right) / 5.702 ; \\
& \operatorname{std}_{7}=\left(X_{7}-2.40\right) / 0.857 ; \\
& \operatorname{std}_{8}=\left(X_{1}-107.5070609\right) / 11.60124498 ; \\
& \operatorname{std}_{9}=\left(X_{1}-33.69543139\right) / 5.150190069 。
\end{aligned}
$$

Restore the standard index variables stdXi of $F_{1}, F_{2}, F_{3}$ expression can get $F_{1}, F_{2}$, $\mathrm{F}_{3}$ expression about the expression of original variable $\mathrm{X}_{1}, \mathrm{X}_{2}, \mathrm{X}_{3}, \mathrm{X}_{4}, \mathrm{X}_{5}, \mathrm{X}_{6}, \mathrm{X}_{7}$, $\mathrm{X}_{8}, \mathrm{X}_{9}$ :

$$
\begin{gathered}
\mathrm{F}_{1}=-0.0001991 \mathrm{X}_{1}-0.0003918 \mathrm{X}_{2}+0.04362 \mathrm{X}_{3}+0.01352 \mathrm{X}_{4}+0.0003231 \mathrm{X}_{5}+ \\
0.008944 \mathrm{X}_{6}-0.07935 \mathrm{X}_{7}+0.01361 \mathrm{X}_{8}-0.007961 \mathrm{X}_{9}-1.7509 \\
\mathrm{~F}_{2}=-0.0002540 \mathrm{X}_{1}-0.0001060 \mathrm{X}_{2}-0.002285 \mathrm{X}_{3}+0.002613 \mathrm{X}_{4}-0.0003440 \mathrm{X}_{5}+ \\
0.08155 \mathrm{X}_{6}-0.1692 \mathrm{X}_{7}+0.01198 \mathrm{X}_{8}+0.07299 \mathrm{X}_{9}-4.7249 \\
\mathrm{~F}_{3}=0.00002220 \mathrm{X}_{1}+0.0006210 \mathrm{X}_{2}-0.003730 \mathrm{X}_{3}-0.007121 \mathrm{X}_{4}+0.0002810 \mathrm{X}_{5}- \\
0.01999 \mathrm{X}_{6}+0.8891 \mathrm{X}_{7}+0.02339 \mathrm{X}_{8}+0.01383 \mathrm{X}_{9}-4.8944
\end{gathered}
$$

Take $F_{1}, F_{2}, F_{3}$ as the independent variable, adults RVD reference values as the dependent variable to using regression analysis, the follwing regression equation is obtained:

$$
\hat{\mathrm{Y}}=19.70-1.194 \mathrm{~F}_{1}-0.157 \mathrm{~F}_{2}+0.644 \mathrm{~F}_{3} \pm 0.63
$$

The $\mathrm{F}=3.059, \mathrm{P}=0.037<0.05$, shows that the regression equation is significant. Make the $F_{1}, F_{2}, F_{3}$ expression which is original variables $X_{1} 、 X_{2} 、 X_{3} 、 X_{4} 、 X_{5} 、 X_{6}$ 、 $\mathrm{X}_{7} 、 \mathrm{X}_{8} 、 \mathrm{X}_{9}$ into the regression equation, convert it into the multiple regression equation about adult right ventricular diameter reference with the original variables:

$\hat{\mathrm{Y}}=19.46+0.0007072 \mathrm{X}_{1}+0.001034 \mathrm{X}_{2}-0.05412 \mathrm{X}_{3}-0.001405 \mathrm{X}_{4}-0.0006351 \mathrm{X}_{5}+$ $0.02903 \mathrm{X}_{6}+0.01243 \mathrm{X}_{7}-0.01033 \mathrm{X} 8+0.03816 \mathrm{X}_{9} \pm 0.63$

In this equation, with $\hat{\mathrm{Y}}$ as the adult right ventricular diameter reference value, $\mathrm{X}_{1}$ as altitude $(\mathrm{m}), \mathrm{X}_{2}$ as annual sunshine duration $(\mathrm{h}), \mathrm{X}_{3}$ as annual average temperature $\left({ }^{\circ} \mathrm{C}\right), \mathrm{X}_{4}$ as the annual average relative humidity $(\%), \mathrm{X}_{5}$ as annual precipitation $(\mathrm{mm}), \mathrm{X}_{6}$ as annual range of temperature $\left({ }^{\circ} \mathrm{C}\right), \mathrm{X}_{7}$ as annual average wind $\operatorname{speed}(\mathrm{m} / \mathrm{s}), \mathrm{X} 8$ as longitude $\left(^{\circ}\right), \mathrm{X}_{9}$ as latitude $\left(^{\circ}\right), 0.63$ is the value of residual standard deviation.

This formula will be a prediction model about obtained by using factor analysis.

\section{3 comparison of the predicted value and the real value.}

Through the above study, the article conclude that the factor analysis prediction model of Chinese adults RVD reference value. Using this model of Chinese adults RVD reference value. Using this model to predicted the relationship between the 
china's regional geographical environment index with the RVD reference value, and will get the comparison of the predicted values and the real values. Choose the contrast about a part of the unit index cases with real value as shown in the figure 2 , can be seen that both had no obvious difference.

Taking Paired sample on both sides T test about adults RVD reference value factor prediction model. The result displayed that : T value is 0.635 of factor analysis model T test, $\mathrm{P}$ value is $0.541>0.05$, in the significant level of $95 \%$, there is no significant difference between the forecast values and measure values, as shown in the figure 2 ,can be seen that factor analysis model to predict the effect is better. 3. Draw the trend map of RVD space distribution

This article selects 2332 nationwide at the country level and above administrative units as the observation point, select observation points: $\mathrm{X}_{1}, \mathrm{X}_{2}, \mathrm{X}_{3}, \mathrm{X}_{4}, \mathrm{X}_{5}, \mathrm{X}_{6}, \mathrm{X}_{7}, \mathrm{X}_{8}$, $\mathrm{X}_{9}$. These nine geographical environment index value, according to the factor analysis model predicted the RVD reference value of regional adults, with the help of ArcGIS accurately match and mapped the distribution trend diagram of the adults RVD reference value(Figure 3). By Figure 3 can clearly get any parts of china adults RVD reference value. Each color represents a reference value range in the diagram, the red area of the reference value range is maximum, the orange area is second, and the blue area is minimal, located in the same color and the reference are same. As seen in figure, Chinese adults RVD reference value are regularly decrease from east to west, the reference value of southeast is smaller, the RVD reference value is higher where the Qinghai-Tibet plateau ,north part of Xinjiang、 west region of Sichuan province, Gansu, Qinghai and other places of china, and the RVD reference value is lower where the east and southeast, north china plain, songnen plain and Sanjiang plain etc.

\section{Discuss}

According to the single correlation coefficient, the correlation is very significant to annual average temperature and annual average relative humidity with the RVD reference value of healthy adults. The correlation is significant to altitude 、 annual precipitation and the annual sunshine hours with the RVD reference value is improved with the altitude and annual sunshine hours increased, it is positively correlated. The 
RVD reference value is lessen with the annual average temperature, annual average relative humidity and annual rainfall is reduced, it is negative correlations. The figure 4 and figure 5 respectively are Chinese altitude and annual average temperature distribution, first can be seen the trend of RVD change compared with altitude, through compared it with the elevation of the tend of variation(Figure 4),from west to east are diminishing, and the roughly direction are same, explanation altitude and RVD reference value is positive correlation ,the RVD increases with the increase of altitude; But comparison with the trend of annual average temperature change image(figure 5), the shape of the both are consistent, but the colour distribution is adverse, explanation annual average temperature and RVD reference value is negative correlated, the RVD decrease with the annual average temperature is increase.

According to the result, it can use factor analysis model equation to calculate the adults RVD reference value in this area if got the altitude, annual sunshine duration ,annual average temperature, annual average relative humidity, annual precipitation, annual range of temperature, average wind speed, longitude and latitude of somewhere. Taking Shanghai as an example, the altitude is $5.5 \mathrm{~m}$, annual sunshine duration is $1986.1 \mathrm{~h}$, annual average temperature is $15.7{ }^{\circ} \mathrm{C}$, annual average relative humidity is $79 \%$, annual precipitation is $1120 \mathrm{~mm}$, annual range of temperature is $24.3{ }^{\circ} \mathrm{C}$, average wind speed is $3.8 \mathrm{~m} / \mathrm{s}$, the longitude is 21.5 , latitude is 31.3 , and obtained by calculation:

$\hat{\mathrm{Y}}=19.46+0.0007072 \times 5.5+0.001034 \times 1986.1-0.05412 \times 15.7-0.001405 \times 79-$ $0.0006351 \times 1120+0.02903 \times 24.3+0.01243 \times 3.8-0.01033 \times 121.5+0.03816 \times 31.3$ $\pm 0.63$

$=20.54 \pm 0.63$

Therefore, the adults RVD reference value is $(20.54 \pm 0.63) \mathrm{mm}$ in Shanghai areas. Can found the RVD reference value in somewhere through the RVD reference space trend chart of adults.

Geographical environment and human health relationship is very closely ,the factors which influence the weather and climate, hydrology, soil, physiognomy, 
biology, etc. The human can change the environment ,but also environment can change human body function ${ }^{[55]}$, people have different functions, cases and causes in different areas, even the body functions is changed, because the transformation of regional environment.

Such as the north are most of tough man, southerners are small and exquisite; and the northerners has cold resistance to adapt to the low temperature, southerners has heat-resisting to adapt to the high temperature. A book about a piece of "the plain question - different theory of France is appropriate" of "The yellow Emperor's internal canon of medicine". "Yellow Emperor asked: doctors to treat disease, the same disease and the treatment is different, the results are recovered, what reason is this? Qibo answer: this is formed by geographical conditions ". This dialogue tells us ,the heavens and the earth is mutual echo, not only must pay attention to the patients themselves in clinical factors, but also should be taken into account the influence of geographical environment.

The environment have obvious regional different rules, it makes a lot of physiological characteristics also showed obvious regionality, the article explores the adults RVD relationship with geographical environment, spatial trends in income distribution diagram macro estimates in most parts of china adult RVD reference value. Geographical environment is a complex, multiple geographical indicators before and after right ventricular could have more and more deep, complex geographical environment and the RVD comprehensive role mechanism remain are research in the further.

\section{The lack of research and prospects}

When collected the RVD reference values, the amount of information is found to be limited, there is no coverage to the comprehensive, such as Hong Kong, Macao and Taiwan as well as no data in the Hainan area, the amount of data in some areas is less . This study mainly is the relationship about geographical elements and RVD reference value preliminary, hope can be collected more and more comprehensive data in the next research, real-time update, and to achieve better effect. 


\section{References}

AnQuan, An Yu.(2014) Echocardiography moved to hypoxia environment for Cardiac function change research. Anhui Medical and pharmaceutical Journal,18(1):120-122. (In Chinese)

Chai Duo, He Xiuying, et al . (2013) Xining area lead to treatment of corpulmonale Dulmonary hypertension 35 cases analysis. Journal of High Altitude Medicine, 23(4):37-39.

ChenLi. (2013) The Vector imaging evaluation completeness right bundle branch block in a preliminary discussion of synchronicity. Ningxia Medical University.

Chu Xianglin(2010). Using two-dimensional spot trocking technology of quantitative evaluation of right ventricular function. Shanghai: FuDan University.

Fu Deyin(2007).Statistical test system of factor analysis .Statistical Study,24(6):86-90. Shi Shuzhong, Song Lijun, et al(2000).Geographic information system spatial analysis function of the application, Inland earthquake,14(1):24-29.

Huang Xiaobing, Wang Chunlin, et al . (2011) .Chronic marrow hyperplastic disease complicated by analysis the clinical characteristics and prognosis of pulmonary hypertension. Journal of clinical Hematology , 24(11):652-654.

Hou Yinglong, Zhang Ningzai, et al (1994). Hypertension left atrial septum and right ventricular changes and its relation with hypertension stage, Med J Chin PLA, 19(5):397-399.

Julien Ternacle, Matthieu Berry, Thomas Cognet, et al. (2013) Prognostic Value of Right Ventricular Two-Dimensional Global Strain in Patients Referred for Cardiac Surgery. Journal of the American Society of Echocardiography, 164 (15): 1685-1689. Lai Wyman W, Gauvreau Kimberlee, Rivera Ernesto S, et al. (2008)Accuracy of guideline recommendations for two-dimensional quantification of the right ventricle by echocardiography. . International Journal of Cardiovascular Imaging, 24(7): 691-698.

Lai Guochao, Chen Chao(2010).SPSS 17.0 Chinese Version:Common functions and application examples.BeiJing:China Meteorological Press,2-250.

Liu YanPing, Li Jinguo.(2008) Echocardiographic evaluation index of the right ventricle. Medical Recapitulate ,14(6):944-946.(In Chinese)

Liuxin Wang Jianhua, et al (2009) The clinical value of echocardiography to evaluate right ventricular function, The medical ultrasound magazine 
(copy),6(2):344-349. (In Chinese)

Lai Xiaojin, Guo Jinchun, et al.(2012) High-altitude plateau acclimation hypoxic right heart remodeling after evaluation. Med J Chin PLA, 37(8):819-822.

Li Xiaosheng, Chen Zhenzhen(2010).How to correct applicat the SPSS software to make composition analysis. Statistical study, 27(8):105-108.

Li Xinxiang, Yan Daoru,et al (2013).Analysis of the clinical value of echocardiography in the diagnosis of corpulmonale.Journal of Medical Imaging,23(10):1651-1653.

Lin Haiming(2012).Some common problems in the application of information analysis, statistics and Decision,(15):65-69.

Lin Haiming, Zhang Wenlin(2005).The similarities and differences between the principal component analysis and factor analysis and SPSS software-with the Liu Yumei, Lu Wendai,ect. Statistical study.(3):65-69.

Lingling.( 2015) The BNP joint Tei index evaluation of right heart function in patients with AECOPD. The national medicine,27(3):34-36. (In Chinese)

Liu Guojiang, DingHui, et al. (2012) Right Ventricular Tei index of right heart function of patients who suffered heart disease from lung disorders. Journal of Guangdong Medical college, 30(2):146-148.

LiuMin, Liangting, et al.( 2014). Double Doppler imaging technique synchronous measurement of E/e' assessment of right ventricular diastolic function in patients with uremia. The medical Journal clinical ultrasound,16(7):454-457. (In Chinese)

Liu Xiaoyu, Wu Weitao, et al.(2014) High altitude check-up crowd heart colour to exceed based data measurement and comparative analysis . Journal of Qinghai normal university(natural science edition),(3):88-92. (In Chinese)

Lu Yongda,TangLing(1999).Plateau climate characteristics and effects on human physiological function. Travel Medical Science,5(1):1-7.

Ma Caihong. (2010) Tissue Doppler and blunt Doppler ultrasound determination of car pulmonary in Tei index contrast research. Qinghai Medical Journal , 40(1):64-66. Ma Caihong, Jin Guoen. (2011).Right Ventricular Tei index in ultrasonic diagnosis of corpulmonale XiNing region and the application of the chronic obstructive pulmonary disease. Hei Longjiang Medicine Journal,24(3):485-487.

Ma Xiuyun. (2011).D CM and ischemic cardiomyopathy in the echocardiographic contrast analysis. BaoDing: HeBei University.

Menghong.(2012) Echocardiographic evaluation of secondary tricuspid new 
indicators,Beijing: Peking Union Medical college Hospital.

Pan Juan. (2012) Human normal echocardiography measured value and influencing factors of pilot study. ChangSha: Central South University.

Qin Jianfeng, Wu Yang, et al (2012).Tei index of right heart function in patients with chronic obstructive Pulmonary disease(COPD) pulmonary hypertension. Chin Heart,24(4):453-455.

Robert Naeije, Chantal Dedobbeleer. (2013) Pulmonary hypertension and the right ventricle in hypoxia. Experimental Physiology,98(8): 1247-1256.

Shang Zhijuan, Congtao, et al.( 2014) Tissue doppler and strain rate imaging evaluation of right ventricular systolic function in patients with mitral stenosis. Journal of Dalian Medical University,36(1):57-61. (In Chinese)

SunXin.(2013) Porous interventional therapy of atrial septal defects clinical research .Beijing : Peking Union Medical college hospital.

Tang Guoan, YangXin.(2006) ArcGIS geographic information system spatial analysis tutorial, BeiJing:Science Press,50-203.

Van der Bom Teun, Winter Michiel M, Groenink Maarten, et al. (2013)Right ventricular end-diastolic volume combined with peak systolic blood pressure during exercise identifies patients at risk for complications in adults with a systemic right ventricle. Journal of the American College of Cardiology,62(10): 926-936.

Vonk M C, Sander M H, van den Hoogen F H J, et al. (2006)Right ventricle Tei-index: a tool to increase the accuracy of non-invasive detection of pulmonary arterial hypertension in connective tissue diseases. European Journal of Echocardiography, , 8(5): 317-321.

Wang Huiying. (2013) .Tricuspid ring the movement displacement automatic tracking technology evaluation research of right ventricular function in patients with atrial septal defeats. Tai Yuan: Shan Xi Medical University.

Wang Li, Wu Yangfeng, et al (2005). Supersonic and enchanted the graph the application study of obstructive sleep apnea syndrome, Chinese Journal of Ultrasonography, 14(6):433-436.

Wang Yong, Liu Yong, et al.(2013) The accelerated plateau of echocardiography in the personnel to assess the Ventricular function. Journal of capital university of medical sciences, 34(6):891-893.

Zou Changhong.(2014) Reverse remodeling of left ventricle in clinical research. Beijing: Peking Union Medical college hospital. (In Chinese) 
ZhangRui,GeJianjun.(2010)The research progress of right ventricular function evaluation. Aahui medical and pharmaceutical Journal, 14(8):877-880. (In Chinese)

Xu Zhanying.( 2014) Echo cardiographic manifestations and clinical analysis MHD patients. Tianjin: Tainjin Medical university. (In Chinese)

Xu Shuzhen, Li Chunling, et al.(2002).Color Doppler echocardiographic evaluation of rapid Tibet recruits, Cardiac function and the change of blood flow in the early research, Med J Chin PAPP, 13(12):711-713.

Yan Chongnian, Yan Jihe,et al(1991) .China's big cities and counties in dictionaries. BeiJing:The central committee of the communist part of china party school press:1-1446.

Yang Haijun, Cui Jianhua, et al .(2008).Yong people to move to high altitude region echocardiographic changes analysis. Journal of China clinic medical imaging, 19(8):595-597.

Yan Hong, Shen Guoquan,et al. (2002)The climatic atlas of the people's republic of China. BeiJing: China Meteorological press,2-250.

Yang Huanyi ,Zhi Guang(2011). 《Supersonic and enchanted the graph specification testing cardiac function and normal》(serial one), The medical Journal clinical Ultrasound, 13(6):430-433.

You Yuguang, Ye Jun, et al.(2006). Tissure Doppler Tei index to evaluate normal right ventricular function as a whole. Journal of Gannan Medical college, 26(2):209-210.

Yao Chengli, Mao Xuejing(1989). The echocardiographic diagnosis of cardiomyopathy(32 cases of attached report), NingXia Medical Journal ,11(4):211-212.

Zhao Tieniu, Wang Hongwu, et al(2010).Vaidation of factor analysis and application. Chinese Journal of Health Statistics,27(6):608-609.

Zhang Jiye, Cheng Ziyi(1981). 120 cases of normal adult echocardiographic measurement and analysis. Medicine and pharmacy of Yunnan,(5):6-10.

Zheng Fang, Dai Rong, et al.( 2013) Tei index to evaluate the seaside recuperate rehabilitation effect of the plateau of right ventricular function in patients with pulmonary hypertension, Cardiovascular rehabilitation medical Journal,22(6):616-619.

Zong Shanghua, Ma Caihong. (2011)Low Oxygen on the impact of right ventricular function in patients with cor pulmonale in plateau area. Shandong Medical Journal,51(32):55-56. 


\section{biosketch}

Yan Liu, female ,born in December 1981,ShaanXi luonan, master degree, geography lecture,college of urban ,rural planning and Architectural Engineering ,Shangluo University.reseach interests include geographical environment and health.

Ge Miao: Institute of Healthy Geography ,College of Tourism and Environment ,Shaan Xi Normal University ,199 South Chang’ an Road ,Xi ‘An ,710062 ShaanXi, China

Table.1 Correlation between the Geographical Factors and RVD Reference Value

\begin{tabular}{ccc}
\hline geographical indexes & r value & P value \\
altitude & 0.284 & 0.023 \\
annual sunshine duration & 0.278 & 0.025 \\
annual average temperature & -0.348 & 0.007 \\
annual averagerelative humidity & -0.335 & 0.009 \\
annual precipitation & -0.287 & 0.022 \\
annual range of temperature & 0.016 & 0.455 \\
annual average wind speed & 0.165 & 0.126 \\
longitude & -0.143 & 0.162 \\
latitude & 0.213 & 0.069 \\
\hline
\end{tabular}

Table.2 Single correlation matrix between nine geographical indicators

\begin{tabular}{llllllllll}
\hline 1.000 & 0.481 & -0.733 & -0.552 & -0.512 & -0.344 & -0.307 & -0.772 & -0.009 \\
0.481 & 1.000 & -0.746 & -0.718 & -0.713 & 0.362 & 0.215 & -0.268 & 0.586 \\
-0.733 & -0.746 & 1.000 & 0.695 & 0.880 & -0.334 & 0.106 & 0.553 & -0.657 \\
-0.552 & -0.718 & 0.695 & 1.000 & 0.709 & -0.281 & 0.063 & 0.498 & -0.483 \\
-0.512 & -0.713 & 0.880 & 0.709 & 1.000 & -0.519 & 0.175 & 0.543 & -0.776 \\
-0.344 & 0.362 & -0.334 & -0.281 & -0.519 & 1.000 & 0.159 & 0.167 & 0.877 \\
-0.307 & 0.215 & 0.106 & 0.063 & 0.175 & 0.159 & 1.000 & 0.457 & 0.092 \\
-0.772 & -0.268 & 0.553 & 0.498 & 0.543 & 0.167 & 0.457 & 1.000 & -0.034 \\
-0.009 & 0.586 & -0.657 & 0.483 & -0.776 & 0.877 & 0.092 & -0.034 & 1.000 \\
\hline
\end{tabular}


Table.3 KMO sampling measurements with moderate Bartlett's test of sphericity value

\begin{tabular}{cccc}
\hline \multicolumn{2}{c}{ Kaiser-Meyer-Olkin } & & 0.633 \\
\hline test of sphericity Bartlett & $\begin{array}{c}\text { approximate value of } \text { X }^{2} \\
\text { degree of freedom } \\
\text { significance level }\end{array}$ & $\begin{array}{c}566.616 \\
36 \\
0.000\end{array}$ \\
\hline components & characteristic value & rate of concentration (\%) comulative contribution (\%) \\
\hline 1 & 4.664 & 51.818 & 51.818 \\
2 & 2.322 & 25.798 & 77.616 \\
3 & 1.031 & 11.451 & 89.067 \\
4 & 0.375 & 4.171 & 93.238 \\
5 & 0.312 & 3.464 & 96.702 \\
6 & 0.166 & 1.842 & 98.545 \\
7 & 0.090 & 0.996 & 99.540 \\
8 & 0.036 & 0.404 & 99.944 \\
9 & 0.005 & 0.056 & 100.000 \\
\hline
\end{tabular}

Table.5 Communalities

\begin{tabular}{ccc}
\hline geographical indexes & start & extract \\
\hline altitude & 1.000 & 0.952 \\
annual sunshine duration & 1.000 & 0.864 \\
$\begin{array}{c}\text { annual average temperature } \\
\text { annual averagerelative humidity }\end{array}$ & 1.000 & 0.901 \\
annual precipitation & 1.000 & 0.723 \\
annual range of temperature & 1.000 & 0.933 \\
$\begin{array}{c}\text { annual average wind speed } \\
\text { longitude } \\
\text { latitude }\end{array}$ & 1.000 & 0.949 \\
& 1.000 & 0.910 \\
\hline
\end{tabular}


Table.6 Component Score Coefficient Matrix

\begin{tabular}{cccc}
\hline & \multicolumn{3}{c}{ components } \\
\cline { 2 - 4 } & $\mathrm{F}_{1}$ & $\mathrm{~F}_{2}$ & $\mathrm{~F}_{3}$ \\
\hline altitude & -0.242 & -0.308 & 0.027 \\
annual sunshine duration & -0.229 & -0.062 & 0.363 \\
annual average temperature & 0.210 & -0.011 & -0.018 \\
annual averagerelative humidity & 0.207 & 0.040 & -0.109 \\
annual precipitation & 0.154 & -0.164 & 0.134 \\
annual range of temperature & 0.051 & 0.465 & -0.114 \\
annual average wind speed & -0.068 & -0.145 & 0.762 \\
longitude & 0.158 & 0.139 & 0.271 \\
latitude & -0.041 & 0.376 & -0.071 \\
\hline
\end{tabular}

Table.7 Descriptive Statistics of Geographical Factors

\begin{tabular}{ccc}
\hline geographical indexes & average & standard deviation \\
\hline altitude & 1006.178 & 1215.0522 \\
annual sunshine duration & 2365.854 & 584.5339 \\
annual average temperature & 12.358 & 4.8139 \\
annual averagerelative humidity & 62.80 & 15.308 \\
annual precipitation & 737.92 & 476.596 \\
annual range of temperature & 24.61 & 5.702 \\
annual average wind speed & 2.40 & 0.857 \\
longitude & 107.5070609 & 11.60124498 \\
latitude & 33.69543139 & 5.150190069 \\
\hline
\end{tabular}




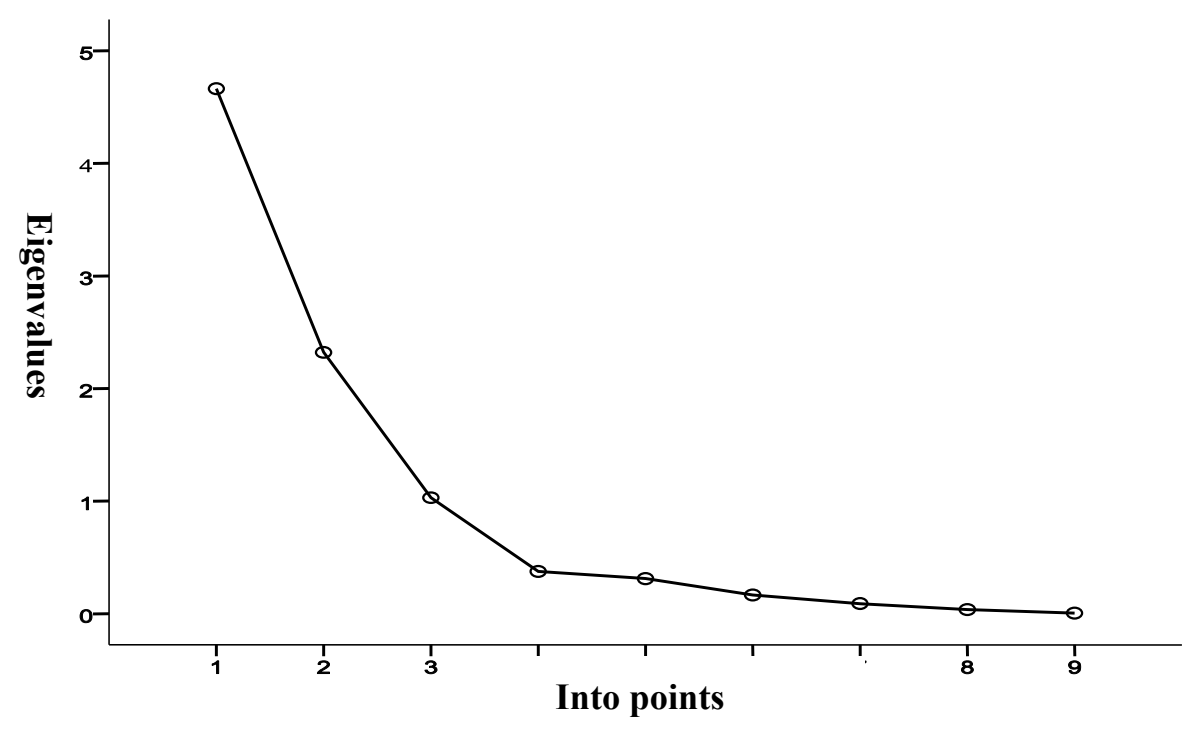

Fig.1 Screen plot

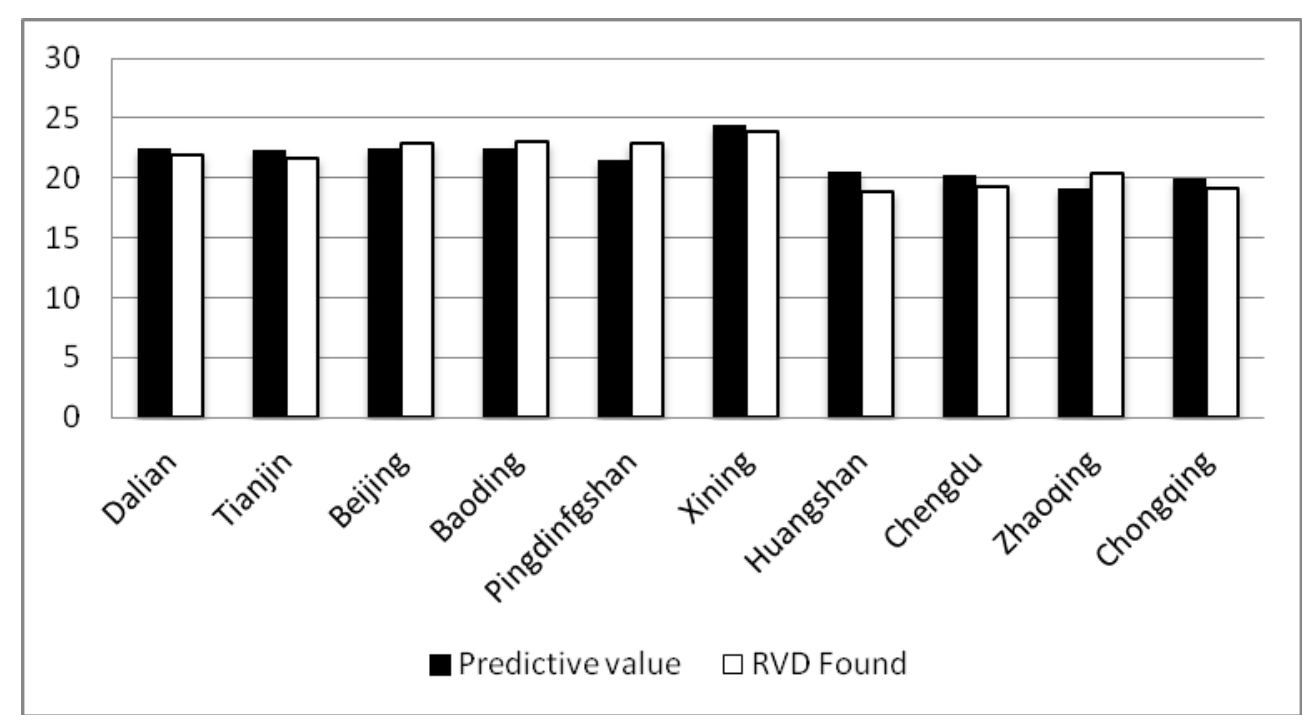

Fig.2 The Real Value and the Predicted Value of RVD 


\section{Legend}

Linear provincial boundaries - State boundaries RVD Reference

$$
\text { (mm) }
$$

$18.00-19.76$

$19.77-20.51$

$20.52-21.48$

$21.49-22.56$

$22.57-23.56$

$23.57-24.39$

$24.40-25.21$

$25.22-26.18$

$26.19-27.15$

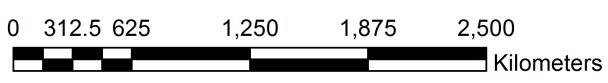

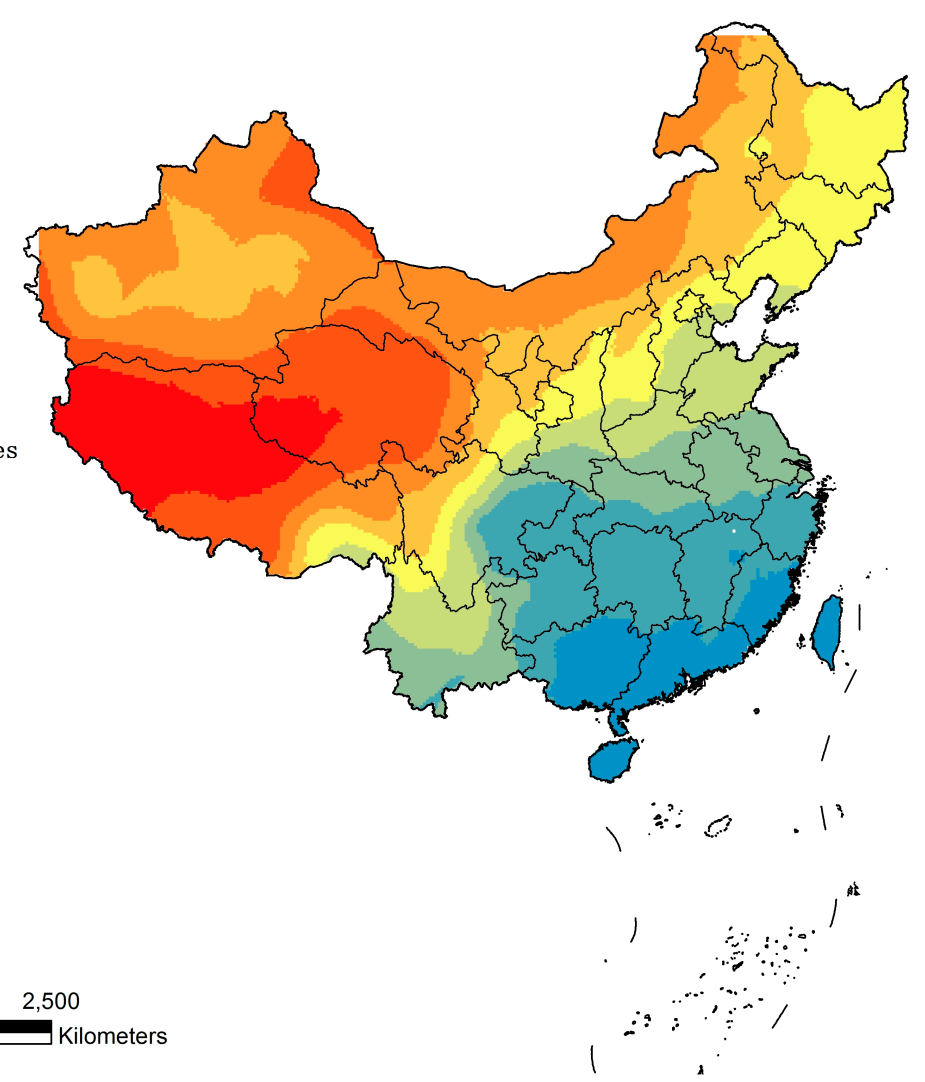

Fig.3 the Distribution Map of Adults' RVD Reference Value

Legend

- Situation provincial boundaries

- State boundaries

Altitude

(m)

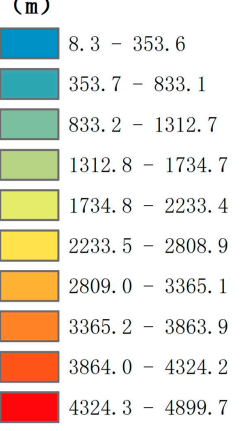

$250 \quad 500$

1,000

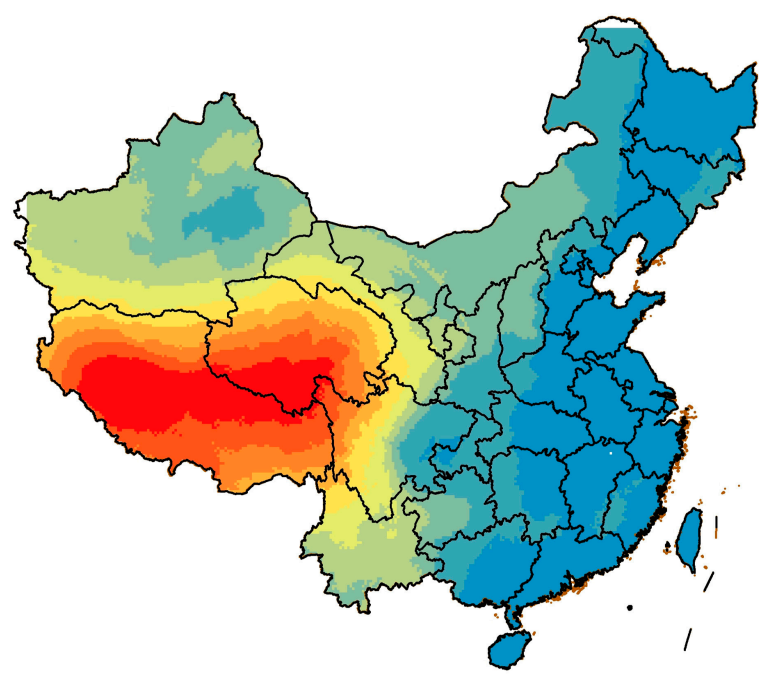

$\because 0.11$

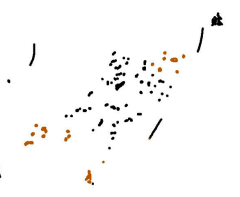

Fig.4 the Distribution Map of Altitude in China 
20 of 20

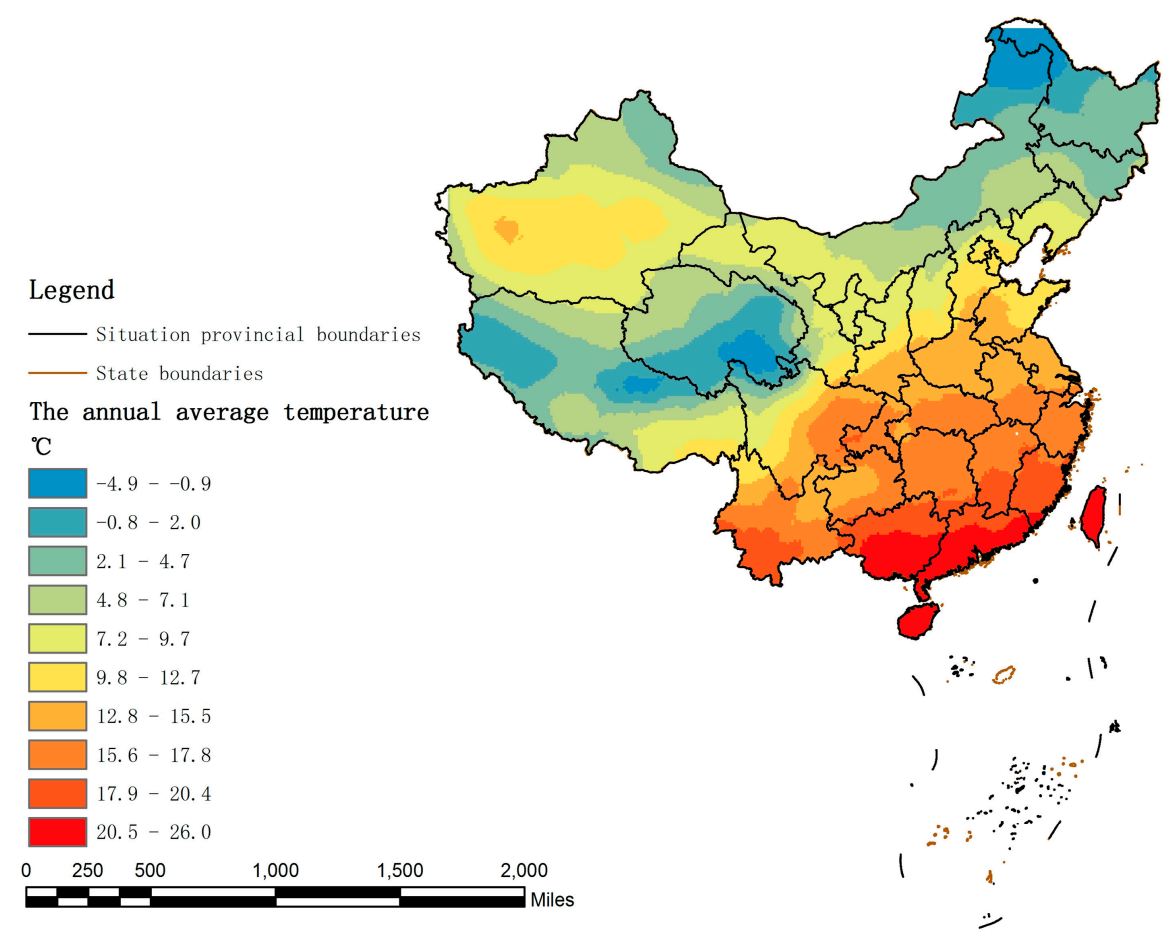

Fig.5 the Distribution Map of Annual Average Temperature in China

(C) 2016 by the authors; licensee Preprints, Basel, Switzerland. This article is an open access article distributed under the terms and conditions of the Creative Commons by Attribution (CC-BY) license (http://creativecommons.org/licenses/by/4.0/). 